\title{
Commentary: Content-Free Awareness: EEG-fcMRI Correlates of Consciousness as Such in an Expert Meditator
}

\author{
Sepehrdad Rahimian' \\ ${ }^{1}$ Department of Psychology, National Research University Higher School of Economics, \\ Moscow, Russia \\ * Correspondence: \\ Sepehrdad Rahimian \\ srahimian@hse.ru
}

\section{A commentary on}

\section{Content-Free Awareness: EEG-fcMRI Correlates of Consciousness as Such in an Expert Meditator}

By Winter, U., LeVan, P., Borghardt, T. L., Akin, B., Wittmann, M., Leyens, Y., \& Schmidt, S. (2020), Frontiers in psychology, 10, 3064.

\section{Introduction}

The search for minimal neuronal requirements for consciousness rests on the premise that there exists a unique state of the human brain, the conscious state, that if one carefully excludes all the confounding cognitive functions, one will be able to isolate those regions that are involved in generating consciousness itself; nothing more, nothing less. I have argued elsewhere (Rahimian, 2021) why this view is deeply flawed and is based on unjustified assumptions mainly from folk psychology. Here I focus on some issues that arise while pursuing such assumptions in scientific paradigms.

Recently, Winter et al. (2020), have conducted an EEG-fMRI study on a participant with professional expertise in meditation and introspection. At some point during the meditation, the participant (TB) has entered an altered state of consciousness which he later described as content-free. Interestingly, the results of the study also show some key changes in his brain function while he was in that state. After carefully considering alternative interpretations of the results, Winter et al take their findings to collectively provide an insight into the neural correlates of consciousness as such, or content-free awareness. While this interpretation is possible, below, I provide two concerns that may cast some doubt on the strength of their conclusion.

\section{Discussion}

First, as authors acknowledge while discussing the limitations of their study, the "contentfree" aspect of the research is based on a post-recording self-report. One immediate concern is that if TB's consciousness was truly content-free, how was he able to recall that very fact? Did he recall a state of not having any particular content in mind, or did he fail to remember anything and consequently concluded that his consciousness must have been without content? Dennett (1988) has provided some useful thought experiments to show how 
sometimes we cannot subjectively tell how our experience might have changed. For instance, is it possible that there was some content in TB's consciousness, but they were simply not encoded, or not recalled? This is where the objective measurements can come in handy, so long as they are sensitive enough to detect the phenomenon at hand.

While Winter et al have used both EEG and fMRI, which has enabled them to cover most bases on spatial and temporal scales, this still does not grant them a strong position to conclude a lack of content in awareness. For instance, even the combination of EEG and fMRI is simply blind to the activities in hippocampal regions in a matter of milliseconds. This insight is currently only accessible through invasive methods such as intracranial-EEG. (Parvizi \& Kastner, 2018). If the authors hypothetically had access to such high resolution, that would have given them a better vantage point to assess whether there was no content in the participant's consciousness, or that he later had reconstructed his subjective narrative as such.

For instance, if we were to see an increase in hippocampal gamma during the supposed content-free stage, we could have later suspected a form of amnesia, as hippocampal gamma has been shown to orchestrate memory encoding (Staresina \& Wimber,2019). Alternatively, if we would not see any significant difference in hippocampal gamma, we had some reason to suspect that perhaps TB has gone through an actual state of "content-free"

awareness. Clearly, without access to such high resolution, we, therefore, cannot make any claims about whether TB truly underwent a content-free conscious state.

Second, it is possible that TB's consciousness has had some content, but he did not encode that information properly. At first glance, this seems unlikely, as TB reported that his consciousness had no content. This is also further supported by the fact that results show a decrease in connectivity in DMN. How could he possibly be encoding or processing any selfreferential information given these results? The answer may be in the breathing.

It is possible that through the course of meditation, TB has been able to solely attend to the sound and the rhythm of his breath (and hence, the frontal alpha-desynchronization), while suppressing the self-referential aspect of that information (and thus, the decrease in DMN connectivity). In other words, instead of thinking "this is the sound of my breath", he simply has entered a state of consciousness in which he can attend to the rhythm of his breath, without thinking anything (at least, not in words). This can lead to many instances of being conscious of the breath, but retrospectively could be reconstructed as a content-free state, as his brain may have simply been habituated to this pattern of breathing and therefore, it would not encode such unnecessary information.

This explanation by no means is the most likely alternative, but it is an alternative; one which this study cannot rule out. Perhaps if a Martian technology could scan the whole brain with high resolution in both spatial and temporal domains, then a case could have been made based on those findings. However, even granting the theoretical assumptions behind the notion of content-free awareness, there are simply too many known unknowns (e.g., hippocampal activity) that need to be addressed before these results can be interpreted as evidence for consciousness as such.

Finally, the findings of this study provide an interesting insight into how a deep meditative state, that is later reported to be content-free, correlates with key changes in DMN connectivity and the dorsal attentional network. 


\section{Acknowledgement}

This work was supported by the national research university higher school of economics (HSE) Program of Fundamental Studies, Russia.

\section{Conflict of Interest Statement}

The author declares that the essay was written in the absence of any commercial or financial relationships that could be construed as a potential conflict of interest.

\section{References}

Dennett, D. C. (1988). Quining qualia. In Consciousness in modern science. Oxford University Press.

Parvizi, J., \& Kastner, S. (2018). Human intracranial EEG: promises and limitations. Nature neuroscience, 21(4), 474.

Rahimian, S. (2021, August 28). The Myth of When and Where: How False Assumptions Still Haunt Theories of Consciousness. https://doi.org/10.31234/osf.io/crbt5. Manuscript submitted for publication.

Staresina, B. P., \& Wimber, M. (2019). A neural chronometry of memory recall. Trends in cognitive sciences, 23(12), 1071-1085.

Winter, U., LeVan, P., Borghardt, T. L., Akin, B., Wittmann, M., Leyens, Y., \& Schmidt, S. (2020). Content-free awareness: EEG-fcMRI correlates of consciousness as such in an expert meditator. Frontiers in psychology, 10, 3064. 